\title{
Using an Action Research Approach to Design a Telemedicine System for Critical Care: A Reflection
}

\author{
Susan Hansen \\ CSIRO ICT Centre and \\ UNSW \\ PO Box 76, Epping \\ NSW 1710 \\ susan.hansen@csiro.au
}

\author{
Toni Robertson \\ UTS \\ PO Box 123 Broadway \\ NSW 2007 \\ toni@it.uts.edu.au
}

\author{
Laurie Wilson \\ CSIRO ICT Centre \\ PO Box 76, Epping \\ NSW 1710 \\ laurie.wilson@csiro.au
}

\author{
Ralph Hall \\ UNSW \\ University of New South \\ Wales, Kensington \\ NSW 2052 \\ r.hall@unsw.edu.au
}

\begin{abstract}
This paper reflects on the Action Research approach adopted in the design of the ECHONET (EchoCardiographic Healthcare Online Networking Expertise in Tasmania) system -a telemedicine system developed by CSIRO (Commonwealth Scientific Industrial Research Organisation) Australia to facilitate the sharing of expertise and services between the Intensive Care Units (ICUs) of a major tertiary hospital and a remote hospital in Tasmania, Australia. The baseline study within this project has been used to evaluate the ways in which the Action Research approach influenced the project directions and its success, allowing the project team to better tailor the system to the clinicians' needs and deal with the unanticipated complications that are common in health projects.
\end{abstract}

\section{Categories and Subject Descriptors}

H5.3 Group and Organisation Interfaces: Computer-supported cooperative work, synchronous interaction

\section{General Terms}

Design, Human Factors, Theory.

\section{Keywords}

Telemedicine, Action Research, Case Study

\section{INTRODUCTION}

Advances in technology are presenting unprecedented opportunities to provide greater access to services for those who live in regional and remote locations. This is particularly the case in health, where specialist services are usually limited to city centres. Those who live in regional or remote locations are therefore often required to travel long distances to gain access to these services. While technology exists that facilitates the provision of these specialist services over a distance commonly referred to as telemedicine systems - they are not always utilised and many projects do not proceed beyond the pilot phase [5]. The reasons for this lack of sustainability extend beyond purely technical reasons, to the social, organisational

OZCHI 2008, December 8-12, 2008, Cairns, QLD, Australia.

Copyright the author(s) and CHISIG.

Additional copies are available at the ACM Digital Library (http://portal.acm.org/dl.cfm) or can be ordered from

CHISIG(secretary@chisig.org)

OZCHI 2008 Proceedings ISBN: 0-9803063-4-5 and political [9]. The CSCW literature identifies that a common reason why systems fail is because the people who are expected to use it don't necessarily get to contribute to the design. We propose that adopting an Action Research approach, actively engaging with the end users throughout all of the stages of the project lifecycle, will improve the chances of telemedicine systems' success. Using ECHONET, a project creating and trialling a telemedicine system, as a case study, this paper explores how adopting an Action Research approach can contribute to designing and implementing a technology that is both useable and used.

\section{ECHONET PROJECT BACKGROUND}

The ECHONET project emerged from a CSIRO regional focus group set up to explore how CSIRO technology using advanced networks could benefit the community of Burnie, located in remote North-Western Tasmania. The initial aim of the project was to create a telemedicine system that would allow the ICUs of the North West Regional Hospital (NWRH) Burnie campus, to access cardiology and ICU services available at the Royal Hobart Hospital (RHH), but not available locally at NWRH. NWRH is approximately $300 \mathrm{~km}$ (5 hours drive) from RHH. ECHONET was designed to help overcome this distance by facilitating the sharing of expertise across hospital sites. This is achieved through the simultaneous transmission of live images from a medical device, (for example echocardiography ${ }^{1}$ images), camera video images and audio between two or three sites over a high bandwidth network connection. The system is portable (for ICU bedside consultations) and can receive up to two and send up to two moving images or video streams at any time. The camera has an adjustable zoom function and is attached to a moveable arm for flexible image capture. Most image-based medical devices can be plugged into the trolley to send their image and the speaker volume is adjustable.

\section{LITERATURE REVIEW}

The telemedicine and Action Research literature provides the context and foundation upon which the current research is based and is briefly summarised below.

\subsection{Telemedicine technology and design}

Much of the telemedicine activity that has occurred has involved the use of standard videoconferencing systems, not specifically designed for healthcare settings [1]. Therefore, the clinicians (or end users of these systems) generally have little or

\footnotetext{
Echocardiography is a diagnostic procedure that uses ultrasound waves to produce detailed moving images of the heart.
} 
no opportunity to contribute to the design of the systems. As a result, the systems do not necessarily adequately address the clinicians' needs and are often complex and difficult to use. In addition to this, in part due to bandwidth cost, low bandwidth telemedicine systems have typically been used that do not produce the quality of video and audio required for clinical diagnostic purposes [11]. A closer match between the needs of the clinicians and the technology is required. Additionally, where possible, the opportunity to iterate or modify the technology as uses and requirements emerge is desirable.

With few exceptions (for example [4]), the implementation of telemedicine systems does not pay adequate attention to understanding the organisational context and environment in which it will be implemented $[9,11]$. Decisions to introduce telemedicine systems are typically made by hospital administrators, without adequate consideration and involvement of the clinicians who will use it [7]. Due to the inadequate attention given to the design, implementation and evaluation of telemedicine systems, despite advances in technology and an intuitively clear compelling case to support the utilisation of telemedicine systems, we are left without strong evidence to support this case. There is a need within telemedicine research to invest in matching requirements more closely with design, applying the frameworks, models or suggestions identified in implementation research to the implementation of telemedicine systems and to better evaluate and assess its impact [5].

\subsection{Action research}

Underpinning the practice of Action Research is an intention of the researcher to effect positive change on the situation within which the research is taking place while simultaneously conducting research, and a collaborative approach between the researcher and subject in reaching this objective and developing understanding [8]. In line with its altruistic intentions and commitment to effecting change, the Action Research approach is characterised by being driven by goals and objectives and exploring characteristics associated with process. The approach contains four distinguishable characteristics. These characteristics as described by Baskerville (1999, p.9) are: An action and change orientation; A problem focus; An "organic" process involving systematic and sometimes iterative stages; and Collaboration among participants. Additionally, Action Research is characterised by the researcher and subjects actively involved as co-participants affecting change in the research environment, the findings discovered can be applied immediately by this active researcher to promote positive change, and the researcher continues to attempt to link theories or ideas with the observed practice. Figure 1 illustrates the commonly cited Action Research cycle adapted from Susman and Everand (1978, p. 588) which includes five phases. These five phases operate within the client-system infrastructure, which is the context and environment within which the research is conducted. This includes the negotiated agreement between the researcher and the 'client' of goals, responsibilities and boundaries [3]. A short description of these five phases is provided in Figure 1.

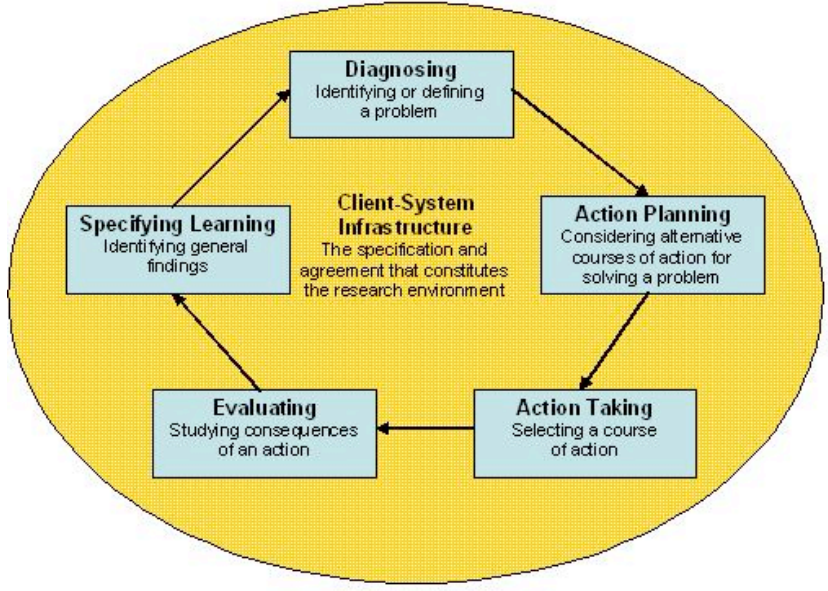

Figure 1. Action Research Cycle

Although the Action Research approach can be and is used by consultants, two key distinguishing features are the motivation - researchers are motivated by scientific prospects and potential for publication, whereas consultants are motivated by commercial benefits; and commitment - researchers make a commitment to the client and the community for the production of scientific knowledge, whereas consultants make a commitment only to the client [2].

\section{METHODOLOGY}

The Action Research methodology allowed us to focus on the real world problem at hand, and inline with a quote by Mumford, "We must not become so concerned with methods that we forget the problems we are trying to solve." (Mumford 1991, p. 26), it was the goals that drove the methods chosen at each step in the project. In the spirit of this Action Research approach, a lot of time was invested in developing and nurturing collaborative relationships with the subjects to develop and implement solutions. While the research design was flexible, it is important to note that none of the events happened by accident or randomly. Rather they were the result of careful planning and continuous revision of the plan based on recent findings. An extensive range of activities took place throughout the project including, focus groups, interviews with key stakeholders, design workshops and a baseline study of current work practice. A detailed exploration of these is outside the scope of this paper. Rather, examples relating to the contribution of the Action Research approach to the project design from the baseline study will be the focus of the paper.

\subsection{Baseline Study}

The baseline study was the first formal activity of the outcome evaluation for the ECHONET project and was also an important part of the Action Research approach adopted. The overall aim of the baseline study was to understand the current working environment of the NWRH and the RHH prior to any new technology being introduced, focussing on the ICUs. How the baseline study contributed to the action research approach is outlined in Table 1.

Table 1. Action Research and Baseline Study 


\begin{tabular}{|c|l|}
\hline Phase & \multicolumn{1}{c|}{ Baseline Study Contribution } \\
\hline Action Planning & $\begin{array}{l}\text { Obtaining clinicians perspectives on how } \\
\text { ECHONET could enhance their work }\end{array}$ \\
\hline Action Taking & $\begin{array}{l}\text { Using the information gathered from the } \\
\text { people who would use the technology to } \\
\text { contribute to selecting a course of action for } \\
\text { project }\end{array}$ \\
\hline Evaluation & $\begin{array}{l}\text { Providing a baseline on which to assess } \\
\text { impact of our proposed intervention }\end{array}$ \\
\hline $\begin{array}{c}\text { Specifying } \\
\text { Learning }\end{array}$ & $\begin{array}{l}\text { Use findings from baseline to inform } \\
\text { project direction and implementation }\end{array}$ \\
\hline
\end{tabular}

There were three methods of data collection for the baseline study. Interviews were the primary data collection tool for the baseline study and were conducted with 15 clinicians at NWRH and RHH. Questionnaires were administered to assess clinicians' approach to technology and their work environment and were distributed to 12 clinicians at NWRH and RHH. Observations were conducted in the ICU's of the hospitals involved to provide a third party, objective snapshot of the work environment, procedures and culture at the hospitals.

\section{FINDINGS AND REFLECTIONS}

Observation and interviewing techniques used in this study and active participation of researchers in the research environment inspired by the Action Research approach helped to:

- Expose some of the gaps between what we were told and what actually happened - for example we observed that several nurses and registrars could be potentially involved in an echo procedure, when we had been previously led to believe it was largely a solo activity. This contributed to giving us a more accurate picture of the environment, people's roles and responsibilities;

- Identify clinicians whose roles were not visible previously for example the baseline study made us aware of registrars, sonographers and clinical nurse educators, who we were not initially told about, but who eventually had significant roles in the ECHONET clinical trial; and

- Expose the hidden and unacknowledged work that often occurs in the medical practice; for example the role of the sonographers, who are highly skilled technicians who conduct a lot of the practical work of the cardiologists.

Active, intentional engagement with clinicians at all of the hospitals revealed a wealth of contextual and practical information that informed project management; contributed to developing relationships with clinicians; and fostered enthusiasm for the project. In addition to this, the baseline study alerted us to the fact that ECHONET's use for teleechocardiography may be limited, however it had great potential to be used for education and training purposes across a range of medical specialities. The impact and significance of the baseline study and the resulting engagement with clinicians was validated in the first month of the clinical trial with its use and non-use. During this first month ECHONET was used on a weekly basis for echo education seminars delivered by the sonographers from RHH Cardiology, and several times for other educational purposes. These were uses that emerged and were a result of the baseline study. However, despite originally being designed for tele-echocardiography, ECHONET was not initially used at all for this purpose. The utilisation of ECHONET for education purposes and relatively low rate of utilisation for tele-echocardiography were anticipated from the baseline study based on observations and interviews. Furthermore, its frequent use for educational purposes, particularly for echo education sessions, was not only anticipated, but was a result of the concerted effort made to involve RHH staff in the project, foster their enthusiasm and work closely with project management to apply suggestions that emerged. While this section addresses only a limited selection of findings from the baseline study, it nevertheless provides compelling examples of how the Action Research approach contributed to this telemedicine system. The remainder of this paper will focus on reflecting on the Action Research experience in this project.

\subsection{The Action Research experience}

Central to the research design, as previously mentioned, was the Action Research philosophy and theory. This section will explore some of the aspects of the Action Research approach that contributed to the success of ECHONET, as well as ethical dilemmas encountered.

\subsubsection{Being there}

Active involvement in the research environment and with the research subjects by the researcher to effect change is an important part of the Action Research philosophy. Close interaction with the clinicians and just 'being there' was an important part of gathering information that people didn't think to mention in interviews, or didn't place significance on. Two of the baseline study outcome examples mentioned came about through being on site and meeting people somewhat serendipitously. An example is our meeting of the clinical nurse educator that encouraged us to consider using ECHONET for education purposes more seriously. Being present on site and informal conversation with clinicians provided insight into the intra- and inter-hospital politics which became invaluable contributions to understanding and negotiating the context and environment we were researching. This informal interaction along with our more formal data gathering processes provided important insight into the informal hierarchies that were in place and how different personalities affected work processes and the work environment.

\subsubsection{Expecting the unexpected}

The ECHONET project experienced many unexpected significant events throughout the project. The ensuing flexible design of the project inspired by the Action Research approach positioned us well to deal with these unexpected events something that a more rigidly structured project may not have been able to cope with. For example, the original plan for the ECHONET project was to connect the ICUs of three hospital locations which included the Mersey hospital. One of the foremost experts of echocardiography was located at the Mersey ICU and it was anticipated that the primary use of the system would be to connect the Mersey hospital site with the Burnie hospital site. After the baseline study was completed and a year after the project began, the only full-time Emergency Department night shift worker at the Mersey hospital was murdered [3]. The hospital was already short staffed and as a result the Emergency Department was unable to operate at night. The hospital was already under review for closure, and this event contributed to the downgrading of the hospital to a 
day surgery centre one month before training of the ECHONET system was to commence. As the ICU in Mersey was being closed, the project had to be re-scoped. Due to the increased involvement of the RHH staff and the new uses that emerged during the baseline study, it was decided that the project could proceed without the Mersey. The third ECHONET trolley, that was previously going to be located at the Mersey, was then placed in the RHH Cardiology department where the sonographers were situated. It is not possible to plan for these types of events in a project. However, our capacity to deal with this situation was enhanced due to the flexible design built into the research project, the project possibilities realised in the baseline study and the relationships and enthusiasm nurtured, particularly in the RHH staff - who actively continued to support the ECHONET project and participate in its re-scoping.

\subsubsection{Planning for the unexpected}

The Action Research approach encourages the use of theory and the literature to inform the study. While unexpected events may occur that can't necessarily be specifically planned for, there are ways that we are able to equip ourselves to anticipate and prepare ourselves for some of them. For the ECHONET project, the main way that this occurred was by becoming familiar with relevant literature. This included both scholarly literature and popular press. To inform the project design and to raise our awareness of potential problems the IS, CSCW, HCI and telemedicine literature were explored. The implementation literature published within the IS field (e.g. [6]) was particularly helpful for identifying potential problems and raising awareness of success criteria in other projects.

\subsubsection{Ethical dilemmas}

While the collaboration and close contact between researchers and clinicians (or other research subjects) yielded many benefits, this contact led to dilemmas when discussing, presenting and writing up research findings. This had been the case at various stages throughout the project when personal relationships with clinicians resulted in challenges when deciding what to present publicly. These were mitigated by taking care to protect individual clinicians, for example censoring sensitive information obtained and remaining politically sensitive and aware throughout the project.

\section{CONCLUSION}

This paper explored how an Action Research approach was able to influence the success of ECHONET and its project directions. Owing to the commitment to understanding work practice and the high level of interaction with clinicians in the hospitals through the baseline study, we were able to identify the risk that ECHONET would not necessarily be used for teleechocardiography purposes. We were also able to identify its potential use for other purposes, such as delivering echo education tutorials. This directly contributed to the success of the ECHONET system, which is increasingly being utilised for the uses that emerged from the baseline study and continues to be used beyond the clinical trial. We were also able to better deal with unanticipated events such as the closure of the Mersey ICU, which could have potentially ended the project. Through this case study we have reflected on how the Action Research methodology contributed to designing and implementing a telemedicine system for a complex hospital environment that is useful, useable and used.

\section{ACKNOWLEDGMENTS}

We thank our many colleagues from CSIRO, the University of Tasmania and the Tasmanian Department of Health and Human Services, including Tony Adriaansen, Hiedi Behrens, Allan Beswick, Steve Broadhurst, Luke Galligan, Kathy Marsden, Greg Peterson, Mark Reeves, Alan Rouse, Marie Saunders, Marcus Skinner, Judi Walker and Sue Whetton.

\section{REFERENCES}

1. Aanestad, M \& Hanseth, O. Implementing open network technologies in complex work practices: a case from telemedicine, in Baskerville, R, Stage, J \& DeGross, J (eds), Organizational and Social Perspectives on Information Technology. Kluwer Academic Publishers, London, 2000, 355-370.

2. Baskerville, R. Investigating information systems with action research. Communications of the Associations for Information Systems, 2, 19, (1999), 2-31.

3. Choy, H. Doctor murder. Mercury, 25 January. Retrieved January 25, 2007, from http://www.news.com.au/mercury/ story $/ 0,22884,21114270-3462,00 . \mathrm{html}$

4. Fitzpatrick, G. TARDIS Evaluation: Report on Final Usage Evaluation of the TARDIS Telehealth System. Document TD-EV-01, Issue 1, 24 July 1998.

5. Klecun-Dabrowska, E. and Cornford, T. Evaluation and Telehealth - An Interpretive Study. In Proceedings of the 34th Hawaii International Conference on System Sciences, IEEE Computer Society (2001).

6. Kwon, T. and Zmud, R. Unifying the fragmented models of information systems implementation. In Boland, R. and Hirschheim, R. (eds), Critical Issues in Information Systems Research, John Wiley \& Sons, Chichester, (1987), 227-251.

7. Linderoth, H. Implementation and Evaluation of Telemedicine - A Catch 22?. In Proceedings of the 35th Hawaii International Conference on System Sciences, IEEE Computer Society, (2002).

8. Robson, C. Real World Research. 2nd edn, Blackwell Publishers, Oxford, 2002.

9. Sanderson, P. Designing and Evaluating Healthcare ICT Innovation: A Cognitive Engineering View. In Proceedings of the 3rd international conference on information technology in healthcare: socio-technical approaches, IOS Press, Amsterdam, (2007), 3-12.

10. Susman, G. and Evered, R. An assessment of the scientific merits of action research. Administrative Science Quarterly, 23, (1978), 582-603.

11. Tanriverdi, H. and Iacono, S. Diffusion of telemedicine: a knowledge barrier perspective. Telemedicine Journal, 5, 3 , (1999), 223-244. 